\title{
Properties of Fibrous Composites with Polyester: A Comparative Analysis Between Sisal Fiber and Pet
}

\author{
Matheus Vinicius Falcao Moreira ${ }^{1}$, Lorrane Carneiro Laranjeira Silva ${ }^{1}$, Joyce Batista Azevedo ${ }^{*}$, Pollyana da Silva \\ Melo Cardoso², Josiane Dantas Viana Barbosa', Daniel Vianna Goes Araujo² \\ ${ }^{1}$ Universidade Federal do Recôncavo da Bahia; Feira de Santana, Bahia; ${ }^{2}$ Centro Universitário SENAI CIMATEC; \\ Salvador, Bahia, Brazil
}

\begin{abstract}
Fiber-reinforced composites represent $75 \%$ of the application of these materials in several industrial segments. It has the purpose of improving technical characteristics and reducing environmental impact through the use of sustainable raw materials such as natural fibers and other fibers from industrial waste. In this sense, the objective of this work was to study and compare the mechanical properties of polyester composites (PL) reinforced with natural sisal fiber and residues of polyethylene terephthalate (PET) synthetic fibers. Initially, we evaluated the moisture and morphology of the fibers. The composites with PL matrix were obtained and the fiber concentration varied by $1 \%, 3 \%$, and $5 \%$ by weight. In the composites, the mechanical properties under flexion and impact resistance were evaluated. We concluded that the level of reinforcement with sisal fibers did not significantly affect the mechanical properties. However, the PET fiber provided significant improvements in the properties of the composite. Thus, the composites reinforced with PET fiber residue have advantages in the development of new material with sustainable characteristics.
\end{abstract}

Keywords: Sisal Fiber. PET Fiber. Polymeric Composites. Mechanical Properties.

\section{Introduction}

Levels of carbon oxide emissions into the atmosphere have become increasingly alarming over the years. This situation becomes worrying due to the accumulation of these gases, identified as one of the main aggravating factors of global warming. This problem led to the development of many studies on new materials with higher renewable potential. Composites reinforced with natural fibers and textiles emerge as alternatives to reduce environmental impact in a scenario in which new materials with improved properties reduce environmental damages [1].

The class of materials that best suits the requirements described and with a wide range of applications are composites. Composites are materials made up of two or more phases on a

Received on 14 September 2020; revised 23 September 2020. Address for correspondence: Profa. Dra. Joyce Batista Azevedo, Universidade Federal do Recôncavo da Bahia - UFRB, Centro de Ciência e Tecnologia em Energia e Sustentabilidade, Avenida Centenário, 697, SIM, Feira de Santana - BA, CEP: 44085-132. Email: joyce.azevedo@ ufrb.edu.br.

J Bioeng. Tech. Appl. Health 2020;3(4):334-340.

(C) 2020 by SENAI CIMATEC. All rights reserved. macroscopic scale, obtained from the mixture of two or more different materials, whose mechanical properties must be superior to those of the constituent materials. To achieve the desired properties in a composite material, each element (matrix, reinforcement, and interface) must have appropriate characteristics. Thus, its properties will depend on the characteristics of its constituents, the relative concentration, the characteristics of the interface, the efficiency in the preparation and transformation processes to ensure the best morphology in the final composite. [2,3].

Polymeric composites reinforced with fibers have wide applications in the industrial and civil construction sectors. Composites are materials that present advantages in their use, as they allow for obtaining particular properties from the coalescence of different materials, whereas this junction results in new applications [4].

Technologically, the significant composites are those in which the dispersed phase is in the form of fibers. These materials combine high strength and stiffness with low weight, as the reinforcement mechanism is associated with the transfer of tension from fiber to the matrix. In this context, this work aimed to evaluate the 
properties of polyester matrix (PL) composites reinforced with two sustainable fibers, sisal fiber and polyethylene terephthalate (PET), and to compare the mechanical properties obtained in composites reinforced with each one of them. Sisal fiber has received particular attention in Brazil, as it corresponds to about $70 \%$ of the commercial production of all solid fiber in the country. Sisal fibers are rigid, inflexible, and have superior strength compared to other natural fibers, in addition to good durability. They consist of cellulose, hemicellulose, lignin, pectin, wax, and water-soluble substances, the first three compounds being responsible for the physical and mechanical properties of sisal fiber [5].

The second fiber studied in this work is PET fiber, a polymer widely used because it is a polyester of great relevance in the industrial context. The application of PET fibers as a reinforcement in automotive components has high prominence due to the excellent mechanical properties and thermal stability intrinsic to the fiber. Academic and industrial interest has guided the development of extensive studies on the crystallization of PET, which is induced by the orientation of its polymer chains, giving rise to structural evolution of practical implications in the optimization of fiber properties. In addition to its triclinic crystalline form, PET forms a mesomorphic phase, which has an intermediate structure between the crystalline and amorphous parts of the polymer $[6,7]$.

\section{Materials and Methods}

The composites were made using two types of fibers as reinforcement:

a. Sisal fiber (Figure 1a), originated from the rope making process of companies located in the city of Conceição de Coité-BA and PET fiber (Figure 1b).

b. PET fiber is an industrial waste generated during the process of obtaining fabrics used in tire reinforcements. This fiber was made available by a factory from the city of Camaçari-BA. The choice of which fiber is due to the opportunity to use industrial waste for the development of new materials, reducing the environmental impact caused by their disposal.

The matrix used accelerated, thixotropic, and low viscosity unsaturated polyester

Figure 1. Fibers used. (a) sisal fiber; (b) PET fiber.
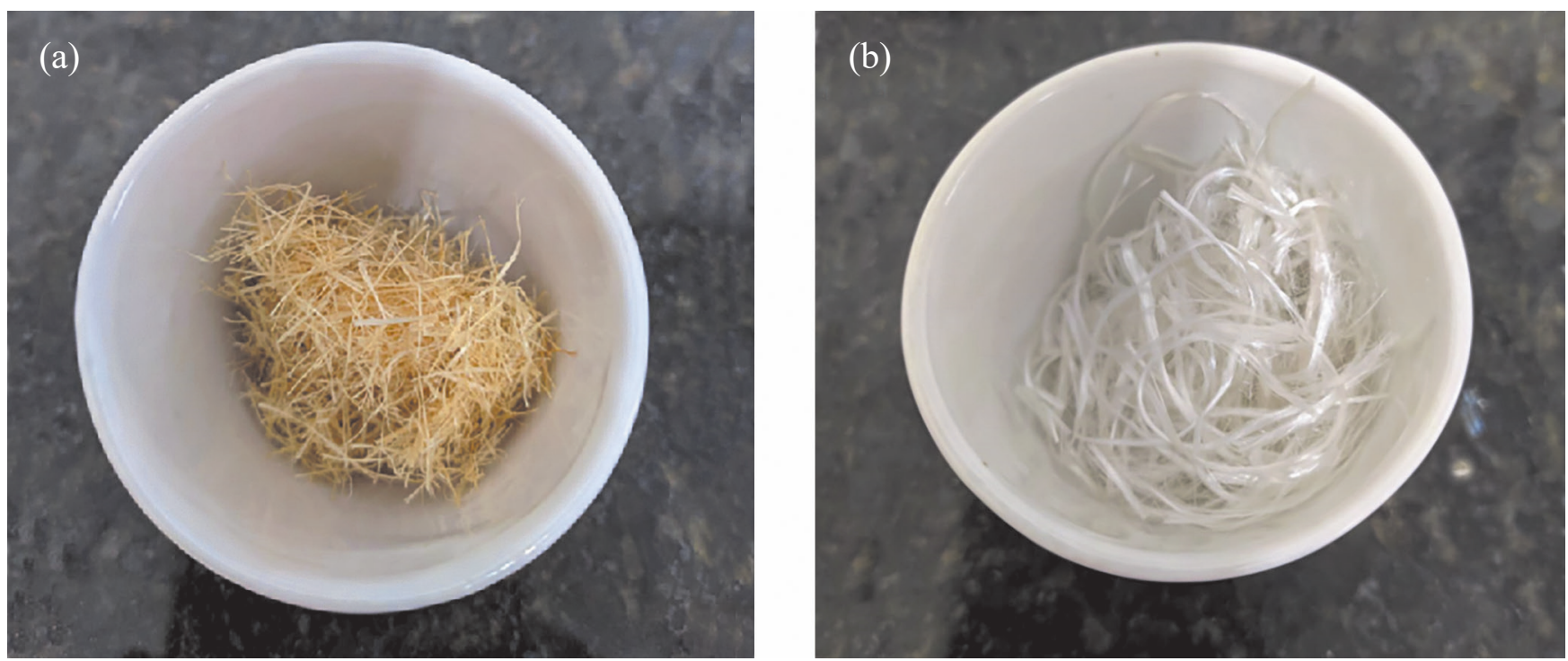
resin. In general, it is a resin indicated for the manufacturing of composite parts by open molding in the processes of Hand Lay Up and Spray Up.

\section{Fiber Humidity Content}

Oven drying was performed to evaluate the humidity. Samples of sisal fiber and PET subjected to temperatures of $80,90,100$, and $110^{\circ} \mathrm{C}$ in a SOLAB model SL-102 greenhouse with air circulation and renewal. The humidity was related to the mass of the samples and the measurement of this parameter was performed every 60 minutes until the mass stabilized. There is following the relation of the equation used to calculate the humidity in percentage:

$$
\text { humidity (\%) }=\frac{(\text { wet mass }- \text { dry mass })}{\text { wet } \text { mass }} \times 100 \%
$$

\section{Fiber Morphology}

Morphological analyzes were performed using scanning electron microscopy (SEM). To carry out the analyzes, the sisal and PET fibers underwent a carbon deposition process on the surface. The procedure was performed with the Denton Vacuum equipment model Desk V. The scanning electron microscopy was performed with the equipment of the brand Jeol model JSM$6510 \mathrm{LV}$.

\section{Composites Manufacturing Process}

The composites were manufactured in a silicone mold following the dimensions required by the ASTM D638-14 tensile strength test standard. The proportion of $5 \%$ by volume of the catalyst was used for the polyester resin and 12 minutes for curing. The composites were obtained with $1 \%, 3 \%$, and $5 \%$ by weight of the fibers. These percentages were defined by experimental observations since higher concentrations would make the molding of the specimens unfeasible in the mold used. After de-molding, the samples were exposed to air for 24 hours until the resin curing process was completed

Then, the specimens were separated, stored, and cataloged according to the compositions.

\section{Mechanical Property of Composites}

To evaluate the mechanical properties of the composites obtained with the different fiber formulations, mechanic tests of flexion and impact resistance were performed on pure resin and composites reinforced with sisal and PET fibers. The mechanical tests were performed at the Mechanical Testing Laboratory at SENAI CIMATEC. To determine the impact resistance, an Instron machine, model CEAST 9050, with a $2.7 \mathrm{~J}$ hammer and IZOD configuration, without a notch, was used, following the ASTM D4812 standard. The flexural properties were obtained through the 3-point test following the ASTM D790-17 standard on the universal testing machine Emic Model DL 2000, and the data were processed using the Tesc Software.

\section{Results and Discussion}

\section{Fiber Humidity Content}

Table 1 shows the humidity for the sisal and PET fibers as a function of the temperature used in the greenhouse.

The results show that the sisal fiber has the highest percentage of moisture at all temperatures used. This behavior was already expected, considering that it is a vegetable fiber with hygroscopic characteristics, in addition to having hydroxyls and other polar groups [8,9]. The PET fiber samples showed relatively low humidity values. The presence of moisture in polyethylene terephthalate resins is critical mainly in its molten form as it can change the intrinsic viscosity of the polymer by changing the forming conditions under temperature [10]. Therefore, in applications where high levels of humidity are not required, PET fibers can be used without prior drying. 
Table 1. Humidity of sisal fibers as a function of time and temperature.

\begin{tabular}{lccc}
\hline Sample & Temperature $\left({ }^{\circ} \mathbf{C}\right)$ & Test time (hours) & Humidity (\%) \\
\hline Sisal fiber & 80 & 4 & 7.71 \\
& 90 & & 6.55 \\
& 100 & & 7.16 \\
PET fiber & 110 & 4 & 7.25 \\
& 80 & & 1.36 \\
& 90 & & 1.49 \\
& 100 & & 1.60 \\
& 110 & & 2.04 \\
\hline
\end{tabular}

\section{Fiber Morphology}

Through the micrographs represented in Figure 2a obtained by SEM, it is possible to verify the longitudinal surface of the sisal fiber. This fiber has an angular or almost cylindrical section, with a diameter of $100 \mu \mathrm{m}$ to $200 \mu \mathrm{m}$ and superficial residues with parenchymal cells distributed equally along with the fiber. These residues impair the interaction of the fiber with the matrix in a polymeric composite [11].

Figure $2 b$ shows the micrograph of the PET fiber, a smooth surface with small surface defects. In other studies, the cause of these surface defects or incrustations on the surface of the fibers is not precisely defined. They can arise during the process of obtaining the fibers or in some drying process $[12,13]$.

\section{$\underline{\text { Impact Resistance }}$}

Figure 3 shows a comparative graph between the results obtained for impact resistance in composites reinforced with both types of fibers.

There was a significant positive effect on this property when added to PET fibers. However, the same increase could not be observed with the addition of sisal fibers, possibly due to the presence of moisture, since moisture generates voids and bubbles during molding. Also, the manual distribution in the manufacture of the samples does not allow for a

Figure 2. SEM of fibers: a) Sisal; b) PET.

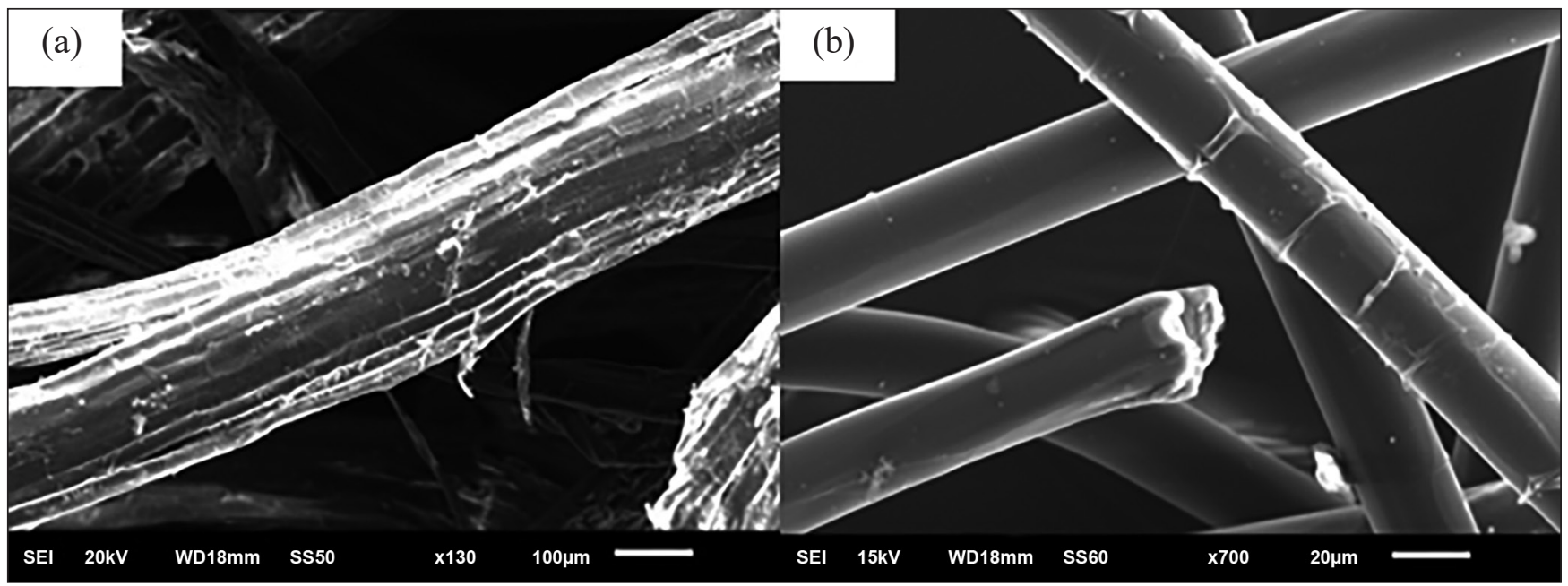


Figure 3. Impact resistance in composites reinforced with sisal and PET.

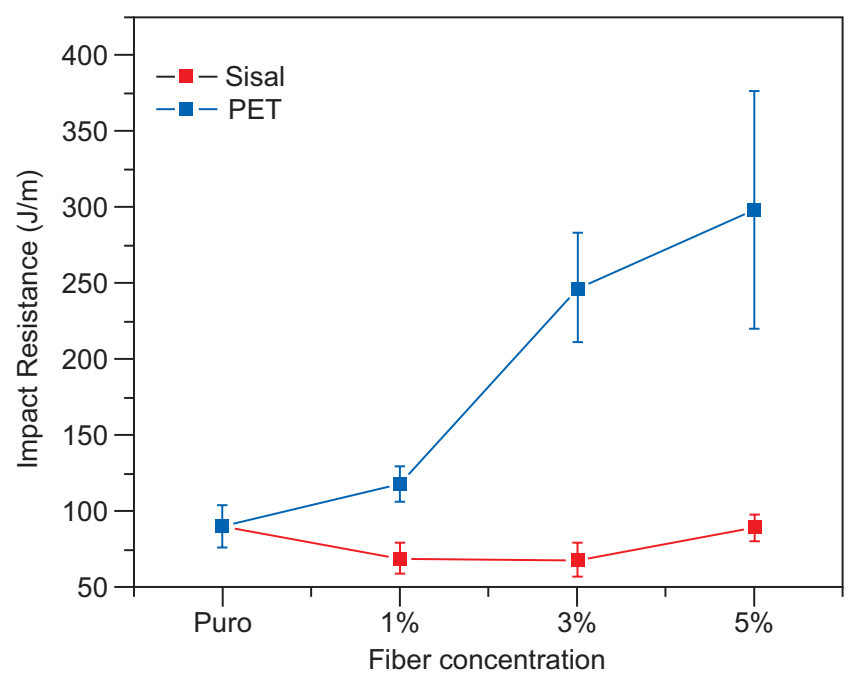

homogeneous distribution of the fibers, possibly causing points of fragility in the composite. The addition of $5 \%$ PET fiber resulted in an increase of more than $300 \%$ in this property. The fibers acted as intensifiers of fracture toughness by the impact. These can show that there is good compatibility in the interface between polyester matrix and PET fibers since the chemical structures present in the matrix and reinforcement composition have an affinity for being of similar families. Similar results were obtained by other researchers, who observed an increase in the impact resistance of the composites with the increase in the content of incorporated PET fibers [14].

\section{Flexural Properties}

Figure 4 shows the results of the flexural properties of composites with sisal and PET. Composites with sisal presented elastic moduli larger than composites with PET. A considerable increase in the modulus of elasticity when adding vegetable fibers has been observed in other studies, varying its maximum values also depending on the type of vegetable used [15]. The elastic modulus is an indirect measure of the stiffness of the materials as natural fibers have a greater stiffness than the polymer (composites expected to show an increase in this property) [16].
The increase in the volumetric fraction in the two types of fiber led to a reduction in flexural strength (Figure 4b). The presence of voids due to failures in the molding step can justify this fact. The voids act as stress concentrating points in the composite, which leads to non-performance and rupture of the material when subjected to stresses lower than those caused by the flexural rupture of the pure polyester matrix [17]. Other factors may also have influenced the result, such as the presence of moisture in the fiber and lack of compatible additives, which hinders the adhesion between the phases resulting in a weak interface. However, although the behavior of the samples regarding the flexural strength of the composites was similar, the composites reinforced with PET fibers obtained great result, which helps to confirm that the interaction at the interface between the polyester matrix and the PET reinforcement has more synergy than at the interface with the matrix and the sisal fiber.

\section{Conclusion}

PET and sisal fibers from industrial waste can be used as reinforcement to obtain polyester composites. A 5\% concentration of PET fiber results in a significant increase in the impact resistance values of the composites. The 
Figure 4. Flexural properties: (a) elastic moduli; (b) flexural strength.

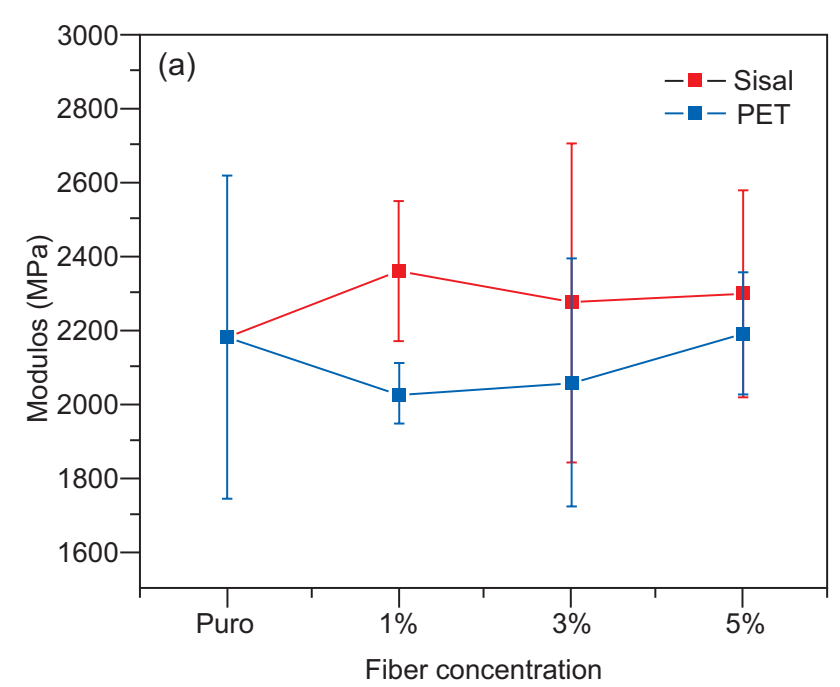

presence of moisture in the sisal fiber may have hindered the adhesion between the matrix and the reinforcement. It also provides the formation of voids during molding.

The flexural strength of the composites reduced in the presence of the evaluated fibers, being lower for higher concentrations of fiber. This behavior can also be associated with the formation of voids in the specimens and poor adhesion between the phases. However, morphological analysis of the interface should be performed for better conclusions.

Finally, composites reinforced with sisal and PET fibers have advantages in the development of new sustainable material since they satisfy demand from society for the search for materials composed of renewable raw materials and waste, reducing the environmental impact caused by disposal.

\section{References}

1. Manjunath RN, Khatkar V, Behera BK. Comparative assessment of Static and Dynamic Mechanical Properties of Glass and PET fiber Reinforced Epoxy Composites. Materials Today: Proceedings 2019;18:4048-4057.

2. Daniel IM. et al. Engineering mechanics of composite materials. New York: Oxford university press, 1994.

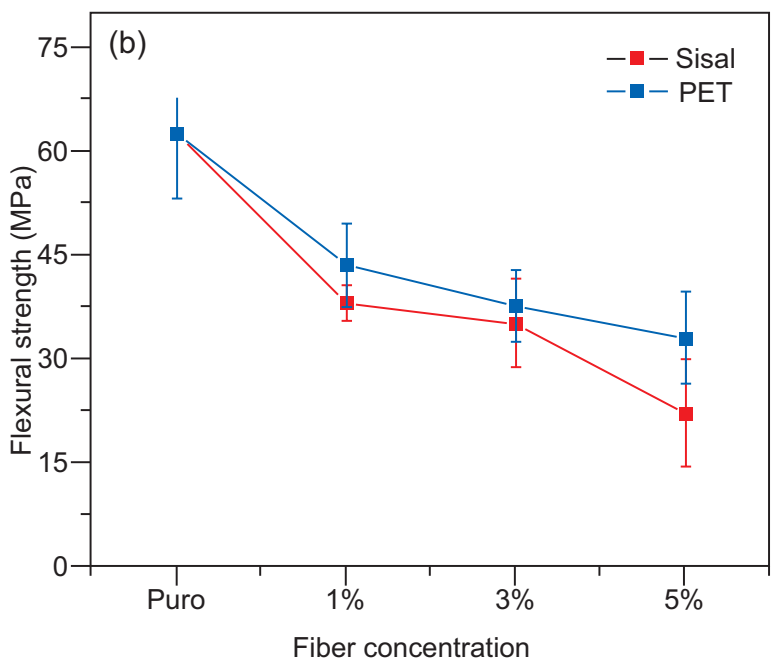

3. Fakirov S, Bhattacharyya D. Handbook of engineering biopolymers: homopolymers. Blends, and Composites", Hanser Gardner USA, 2007.

4. Saba N, Paridah MT, Jawaid M. Mechanical properties of kenaf fibre reinforced polymer composite: A review. Construction and Building materials 2015;76:87-96.

5. Sapuan SM. et al. Mechanical properties of woven banana fibre reinforced epoxy composites. Materials \& Design 2006;27(8):689-693.

6. Wang C, Lee M-F, Wu Y-J. Solution-electrospun poly (ethylene terephthalate) fibers: Processing and characterization. Macromolecules 2012;45(19):79397947.

7. Mishra B, Gupta MK. Use of randomly oriented polyethylene terephthalate (PET) fiber in combination with fly ash in subgrade of flexible pavement. Construction and Building Materials 2018;190:95107.

8. Fabiyi JS. et al. Effects of wood species on durability and chemical changes of fungal decayed wood plastic composites. Composites Part A: Applied Science and Manufacturing 2011;42(5):501-510.

9. Mohammed L et al. A review on natural fiber reinforced polymer composite and its applications. International Journal of Polymer Science 2015.

10. Pirzadeh E, Zadhoush A, Haghighat M. Hydrolytic and thermal degradation of PET fibers and PET granule: The effects of crystallization, temperature, and humidity. Journal of Applied Polymer Science 2007;106(3): 1544-1549.

11. Dhand V. et al. A short review on basalt fiber reinforced polymer composites. Composites Part B: Engineering. 2015;73:166-180. 
12. Farah S. et al. Morphological, spectral and chromatography analysis and forensic comparison of PET fibers. Talanta 2014;123:54-62.

13. Betioli AM. et al. Degradação de fibras de PET em materiais à base de cimento portland. 2003.

14. Asgari M, Masoomi M. Thermal and impact study of PP/PET fibre composites compatibilized with glycidyl methacrylate and maleic anhydride. Composites Part B: Engineering 2012;43(3):1164-1170.

15. Hillig É, Iwakiri S, Andrade MZ, Zattera AJ. Caracterização de compósitos produzidos com polietileno de alta densidade (HDPE) e serragem da indústria moveleira. Revista Árvore 2008;32(2):299310

16. Carvalho MS, Azevedo JB, Barbosa JDV. Effect of the melt flow index of an HDPE matrix on the properties of composites with wood particles. Polymer Testing 2020:106678.

17. Zarate CN, Aranguren MI, Reboredo MM. Influence of fiber volume fraction and aspect ratio in resol-sisal composites. Journal of Applied Polymer Science, New York, 2003;89(10):2714-2722. 